\title{
Integrity of Photography in Visual isuar Communication
}

\author{
HusainiYaacob $^{1}$, Salinatin Mohamad-Saleh ${ }^{2}$ \\ 1Fine Art Department, School of Arts, Universiti Sains Malaysia, Penang, Malaysia \\ Integrity Unit2, Universiti Sains Malaysia, Penang, Malaysia \\ husaini@usm.my (HusainiYaacob1),salinatin@usm.my (Salinatin Mohamad-Saleh 2)
}

\begin{abstract}
Integrity is truthful and unaffected quality. Truthful images in visual communication are aligned with an ethical photography code of ethics. Since the long time ago even during World War II, images had been the tools for propaganda to affect the mind of the public and cause behavioral change among the human society. Various studies have been emphasizing the impact of integrity photography as a visual communication tool. Truthful photography is used as evidence of cases or even to preserve histories of situations and environment for the future generations to see and learn from it. Nevertheless, in this era, the integrity of photography is questionable. Many images in pictures have been altered or staged to be manipulated for some other agendas and did not appear as what it used to be original. In each photograph, the integrity of it relies on the photographer himself, of how much accountability, he holds to bring out the true issue of what had really happened in the actual scenario. Some photographer purposely manipulates their pictures for the purpose of commercial value. In the past, and more recently, various images have been edited to meet the requirements of situations that succumbs to portray the truth of what had actually been photographed. However, some manipulated photographs could be of high value and being sought of; as such the illustrated photography and mixed media photography. For those conventional photographers, many have asked, "where does the integrity lie"? But for those artistic photographers, some would say "why not, it's digital'. This paper discusses the importance of integrity photography amidst the manipulated photography as a visual communication tool for the human society.
\end{abstract}

Keywords Photography, Integrity Photography, Visual Communication, Integrity Images

\section{INTRODUCTION}

The photograph is an accurate kind of record that has been taken from the real event. From the second that the camera is clicked and a moment is captured, a record has been given birth to the world. Photography is a form of visual communication; it communicates to viewers without voice but with messages. Every message from the image brings education to the minds of the viewers (Mustaffa Halabi, 2011). In the olden days when the camera was invented, photographs were taken on the basis of 'as is' and 'where is' basis. People were overwhelmed to have themselves pictured and were fascinated to keep moments in memories. Nevertheless to date, technology has invented the digital camera. This is where the challenge has become more severe.

The word 'integrity' brings the meaning of being truthful and unaffected. In the Stanford Encyclopedia of Philosophy (2013), integrity amongst the interpretations is 'to maintain the identity'. Hence, the photograph which has not been affected by alteration or manipulation means the integrity photography.

In the world of photography, anyone would imaginephotography that involves the process to produce photographs and the photograph itself. But, less people would think about how we perceive the photograph to grasp the meaning for understanding. In some developing countries, not many people were taught to appreciate the message in photograph as art of visual communication; unlike in developing countries where appreciating photographs have been taught in school about how to perceive the photograph. However, the understanding of a picture depends on the person's experience, knowledge, culture, surrounding, and emotional state at the current time he is viewing the picture. In visual communication, understanding a picture that portrays the original condition of the real environment and understanding a picture that has been edited, is so much different from what an image could bring to the human society.

In the development and advancement of technology, digital photography exists. There are plenty of ways that photographers can manipulate the pictures they took in their own accord for their use in something of benefit to themselves or to benefit certain groups of people. For example, a model or artist commonly seen on a poster or magazine front page is often displayed

as a perfect figure with muscular, smooth and long legs to attract the attention of the audience while the originality of the subject has been depicted. Another example of a picture about people gathering in a peaceful national day holding flag could have been edited to hold some other harmful objects through the intention of photographer to raise propaganda on certain issues; this could cause major chaos among the society who were not there to witness what had really transpired at the real gathering. The application of certain 
programs or softwares to add or create an element in the image with a specific requirement has led to the integrity of the photo being detriment and challenged.

For some photographers, extreme edited pictures are not considered as photography, but they are called as digital art. They argued that the only basic principle of integrity of a photograph is what that can only be produced in conventional photography; in the dark room, with the brightness, contra, burning and color balance. In this case, the photographer's concept of photography is very important. Hence, before recording a picture, the photographer might have taken into account the whole idea of why the picture has to be taken, the location, the right composition, and to make sure the light exposure is alright manually. Every picture that has been taken is based on instances and most important, instances that are truthful to the audience in the particular society to understand. Most of these photographers are highly skilled and therefore, they should understand all the processes and principles of shooting pictures. Once the photographers have pressed the recording button, they cannot turn it back. However, we know that nowadays, editing techniques can be done with ease and as a result, the image is no longer an integrity photography of what the audience is supposed to see and understand about what has really been going on.

\section{INTEGRITY OF IMAGES}

Integrity in photography involves trust and responsibility which act as the important roles to gain trustworthiness. As a photographer, especially in the areas of journalism and documentary, they are responsible to channel information and deliver the right message to the human society through visual communication. It is just as simple as what Lewis Hine has pictures to show the injustice of the working children from which had attracted the society and the government to implement labor laws by not allowing underage children to work as laborers in factories.

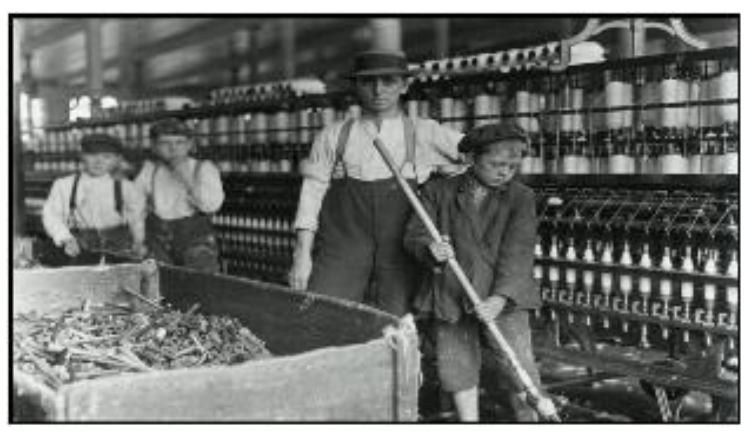

Fig. 1 Cotton Mill, Child Labour, Lewis Hine (1908)

The integrity of a photograph or document images could be the evidence of some important cases. Their
Photographs could also be of a historic one day in time to come. Another simple, truthful thought was by henri cartier-bresson, who had emphasized that photography is related to 'decisive moment'. The capturing of a 'decisive moment' has been already the truth that is very close to upholding the integrity of a photograph. In this instance, the photographers are prohibited to alter or edit the recorded images so that the integrity of the pictures can be maintained as mentioned by sebastio salgado, a social documentary photographer who stated that photo production is the responsibility and the role of a photographer. According to selgado, the responsibility of the photographer is not only to capture the correct picture at the correct time and place, but more importantly, to create a discussion on the problems that has actually happened to trigger the ideas among human society to rise and be sensitive to the problem in order to find solutions to overcome a situation emphasized in the picture. speechful

Certainly, as what selgado presented was a

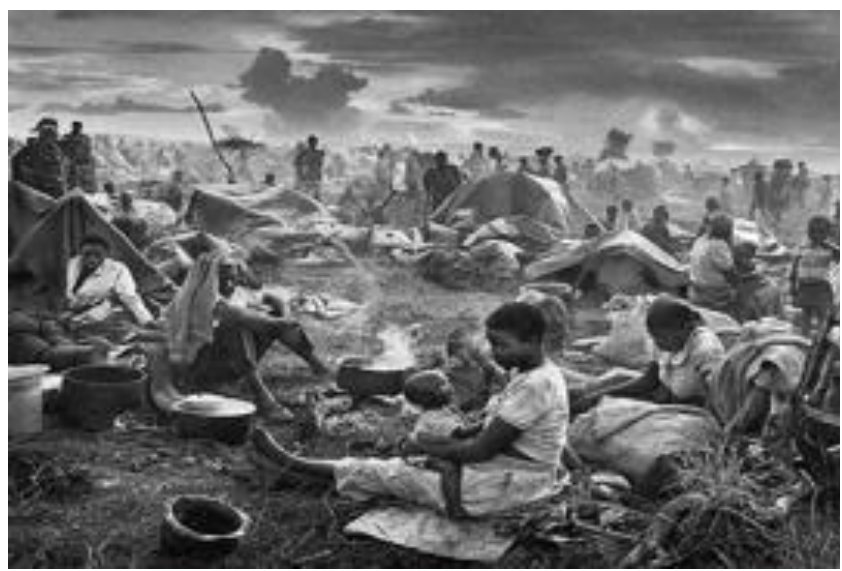

Fig. 2 rwandan refugee camp of benaco, tanzania, 1994, sebastiao salgado

Piece of picture, from subjects that are near to those in kilometers away, from the ground to the sky. Each and every detail that he emphasized in his picture makes the mind works so much thinking about the situation. Almost everyone who sees his picture would feel as if being in the situation of the refugees.

\section{MANIPULATION AND DETECTION OF IMAGE?}

As the era moves forward now in digital technology, we must admit that almost each and every one of us have our own camera in hand through our mobile phones. However, not many who realize that manipulation happens every day in almost every click. Nowadays, camera has been considered as a data-collection device (Campbell, 2014) whereby situations or subjects can be pictured in less than a second and the picture has readily been edited by the built-in features of the mobile. Photographs can immediately be sent or posted in 
seconds to around the globe which could be used to gain feedback from people in the media groups.

In some instances, pictures are taken as foggy and cold through the features available in the mobile phones, whereas the real situation has been a sweating and hot environment. For this reason, we have to understand that what we see and immediately believe doesn't mean, how it looks like in the real life. Most common as such when a mole on a person's nose is removed to make the picture look clean and flawless. A simple explanation is, we know that some ladies looked beautiful and flawless in pictures, but they do not turn out to be who they are in actual complexion. Manipulating or faking a photograph can raise emotions, perceptions and controversies. Thus, would you consider integrity photography or manipulated photography?

According to Campbell (ibid.), pictures are considered to alter when there involves an addition of the elements in the picture or if it involves a subtraction of elements that are supposed to be in the picture. If any of these incidents occurred, they are considered as altered. Campbell elaborated that the jury of World Press is concerned about an alteration in the process of choosing and considering photographs for its annual contest. To detect any manipulation in photography, Campbell also relates how to detect manipulated images; whenever a picture has been manipulated, the picture will be looking at its content of the image and whether it applies substantial toning to obscure the details of which could lead to altering the content. Applications some computer softwares or programs can edit some unwanted images from the original image.

Some photojournalists would think that they take pictures by shooting the scene and they use different lens, filters, aperture and shutter speed settings and in some instances, taking a picture in different posture will make a person look unnaturally tall or short. This is not the reality as it is too.

Worryingly, Greene (2015) mentioned that there were many photographers who staged photos. Staging photos involve the ethical of the photographers themselves and thus, the effort by the World Press

organization to create rules and code of ethics for their contest is a great effort that sparks the need of integrity that is in demand in the production of photographs.

\section{BENEFITS FROM MANIPULATION}

In the genre of illustrated photography and mixed media, photography, photography production has been manipulated as art. Most of the pictures are intended for money making or used as magazine covers and even in advertisements to attract the attention of viewers. Although knowing that these photographs are not of the real image, but what people seek in the photograph is the beauty of the photographic art. Some people are willing to buy the picture for collection or as decoration even though knowing that the quality of a real photograph lies in the original condition of the subject in the picture taken without any manipulation. "People ignored the value and importance of photograph" (Ismail, 2013, cited in Husaini, 2013, pg. 131).

\section{INTEGRITY PHOTOGRAPHY IMPORTANT?}

Weber (in Campbell, ibid.) has emphasized that 'photographs lie, photographers do not'. In actual fact, the integrity of photography wants to tell how the picture has to be told, but some of the media and competitions do not let it be that way (Weber, in Campbell, Ibid). When this happens, the public could lose trust in the media. Along the way, how could the media gain trust from the humane societies again? As photographers, it is encouraged that accountability is held overtime to gain trust from the public. This has also been mentioned by Mundial Photographer (2016) that the photographers should hold integrity in their tasks, sometimes accepting the instructions of not wanting who to be in the photograph, or taking a picture of someone a part of the other one and so on. The task is not easy, but the upholding of integrity in every photography task is important.

\section{CONCLUSION}

Some people would think that even Ansell Adams had done fine-tuning with the exposures. So, does that action has been considered a manipulation in post-processing? As photography reaches out to people through the eyes that allow us to capture and blend the message in our mind to think, it always has something to be criticized by other people. Hence, different people could vary in opinions on one particular photograph (Berger, 1998). Opinions and criticisms on photographs should be taken from various external

parties - because "different criteria illuminate different aspects of artwork" and that could allow us to collect as many views as we could on a photograph in order to appreciate it (Barrett, 2000). Nevertheless, in this issue, different views and opinions on the integrity of still photography could lead to a never ending discussion. In some discussions on photographic illustrations, they have expressed that reconfiguring photographs, although those have been an unstable fundamental, however, it is still a continual process that has been done alongside the social or cultural field. Hence, many people questioned the ethical conduct of photography. Photographs must reveal the real environment and real information from the true situation, for people to see and think. Giving a thought on this issue, let us think how could a photograph lie? Sontag (1979) in her book 
'On Photography' has emphasized that photography is the representation of a real life situation which differs from painting. A painter could decide whether to have or not, have a subject in it depending on the artistic presentation of his own artwork. In photography of the current era, the greatest challenge is to produce a photography of reality. But the simplest action to do is to produce the reality; no removal or addition, no changes from worse to better. Just present the truth of the hidden aesthetics so that the photograph has its value.

Therefore, it is best to consider these three main aspects of integrity in photography that should be considered and implemented by the photographers; the truthfulness of the situation portrayed, the accountability of the photographer to bring the real issue and the trustworthiness that the public has towards the photographers should be kept and handled well whenever taking a photograph. Besides, if the code of ethics such as of the World Press if could be implemented in all organizations, all photographers or photojournalists should abide to the rules and code of ethics of photography in the organization they are attached to.

\section{REFERENCES}

[1] Azahari, MHH (2011). Photography : Its significance Strands and Values in Education. University Publication UiTM, Malaysia: UniversitiTeknologi MARA.

[2] Barrett, T. (2000). Criticizing Photographs, an Introduction to Under-standing Images, 3rd Ed., McGraw Hill.

[3] Berger, A.A. (1998). Seeing is BelievingAnIntroduction to Visual Communication, 2nd Ed., Mountain View, Mayfield Publishing Company.

[4] Campbell, D. (2014). The ntegrity of The Image: Current practices and accepted standards relating to the manipulation of still images in photojournalism and documentary photography. A World Press Photo Research Project.

[5] Freedman, R. (1994). Kids at Work: Lewis Hine and the Crusade Against Child Labor, Houghton Mifflin Company. New York.

[6] Greene, S. (2015). Staging, Manipulation and Truth in Photography, 16 October 2015, The New Y ork Times, https://lens.blogs.nytimes.com/2015/10/16/staging manipulation-ethics-photos/?mcubz $=0$

[7] Hine, L. (1966). Photographers on Photography, Nathan Lydas, Prentice-Hall Inc.

[8] Ismail, H. (2013). Personal Interview on Social Commentary, Photography, Penang, Malaysia.

[9] Mundial Photography (2016). The Integrity of a Photographer. http://www.mundialphoto.co.uk/blog/the-integrity-ofa-photogragpher

[10] Salgado, S. (2016). Exodus (Fo) TASCHEN; PckHar/Pa ed.

[11] Sontag, S. (1979). On Photography. London: Penguin Books.

[12] Yaacob, H. (2013). Social Commentary Through Photographic Representation in Malaysia, Atlantis Press.

\section{Biographical Data:}

Husaini Yaacob, a holder of PhD Degree in Photography currently teaching Photography (Fine Art) at Universiti Sains Malaysia (USM), Penang and can be contacted at saniyaacob@yahoo.com.

Salinatin Mohamad-Saleh, having a Master's Degree in Visual Communication from MARA University of Technology, Shah Alam, Selangor, and currently attached to Integrity Unit of USM can be contacted at salinatinsaleh@gmail.com 